DOI 10.15593/2224-9354/2017.4.22

УДК 378.07: 005.91

\title{
С.В. Кульпин
}

\section{ЭНДАУМЕНТ-ФОНДЫ КАК ЭЛЕМЕНТ НЕЛИНЕЙНОЙ МОДЕЛИ ЭКОНОМИЧЕСКОГО РАЗВИТИЯ ВУЗА}

\begin{abstract}
Нелинейность в экономической среде высшей школы России стала проявляться с переходом экономики страны на капиталистические рельсы. Советская модель финансирования высшей школы была сугубо линейной. Других источников поддержания бюджетов вузов, кроме государственного заказа на подготовку кадров и проведения исследования, практически не было. Результат развития вузов был строго определен и предсказуем. Современные вузы стараются найти дополнительные пути фринансирования своей деятельности, что говорит о проявлении нелинейности в экономико-финансовых моделях обеспечения работы вузов.

Одним из проявлений нелинейности развития экономики вузов в России стало развитие фондов целевого капитала, или эндаумент-фондов. Это следствие того, что вузы стараются идти по пути большей независимости и автономии от государства. Капитализация экономики страны побуждает вузы искать новые статьи дохода. Некоторые эксперты расценивают фонды целевого капитала как институты социальных инвестиций, не связанных с ростом государственных расходов и коммерциализацией социальной сферы. Российские вузы переняли опыт западных стран, где опыт создания эндаументов измеряется столетиями. Можно говорить о том, что фонды целевого капитала в разных странах имеют схожие свойства, если их рассматривать с точки зрения институтов рыночной экономики, но при этом они могут различаться в контексте законодательства, истории страны, культуры и т.д.

В статье рассматриваются перспективы развития фондов целевого капитала в российских вузах, их целесообразность, основные проблемы их формирования и развития.

Автор предлагает обратиться к успешным практикам реализации эндаументов-фондов в российском высшем образовании и классифицировать эндаумент-фонды на основе кейсов создания и развития эндаумент-фондов в российских вузах.

Научная новизна исследования состоит в актуализации современного состояния фондов целевого капитала в российских вузах, а также в попытке их классификации.

Ключевые слова: эндаумент-фонд, фонд целевого капитала, нелинейная модель экономики образования, классификация эндаумент-фондов, российские вузы.
\end{abstract}

Введение. Нелинейная модель высшего образования в макрорегионе на сегодняшний день является актуальным объектом исследований в российской науке. Существует объективная необходимость перехода к такому виду модели в условиях экономической и социальной неопределенности [1].

Одним из этапов исследования подобного перехода является оценка нелинейности в экономике вузов России и перспективы ее развития в ближайшем будущем. В более раннем исследовании автором было отмечено, что нелинейность в экономической среде высшей школы России стала проявляться с переходом экономики страны на капиталистические рельсы [2, с. 72].

(C) Кульпин С.В., 2017

Кульпин Сергей Владимирович - канд. экон. наук, ст. преподаватель кафедры интегрированных маркетинговых коммуникаций и брендинга, Институт государственного управления и предпринимательства ФГАОУ ВО «Уральский федеральный университет имени первого Президента России Б.Е. Ельцина», e-mail: s.v.kulpin@urfu.ru. 
Советская модель финансирования высшей школы была сугубо линейной. Других источников поддержания бюджетов вузов, кроме государственного заказа на подготовку кадров и проведения исследования, практически не было. Результат развития вузов был строго определен и предсказуем. Современные вузы стараются найти дополнительные пути финансирования своей деятельности, что говорит о проявлении нелинейности в экономико-финансовых моделях обеспечения работы вузов.

Ранее автором было выделено четыре основных элемента проявления нелинейности в экономике вузов: сочетание бюджетного и контрактного приема в вузы, «болезнь издержек» на рынке высшей школы, развитие фондов целевого капитала, грантовая активность представителей вузов [2, с. 74-75]. К данным элементам стоит еще добавить реализацию хозяйственно-договорных отношений между вузами и субъектами экономики региона.

Данное исследование посвящено одному из элементов нелинейного развития экономики вузов - фондам целевого капитала, или эндаумент-фондам.

Статья содержит две основные части. В первой автор старается доказать, почему эндаумент-фонды - это необходимый элемент нелинейной модели развития высшего образования. Во второй автор приводит данные по динамике развития эндаумент-фондов в российских вузах и основных тенденциях в этой области. Также автор предлагает классификацию эндаумент-фондов по различным классификационным основаниям.

Эндаумент-фонды как проявление нелинейности в развитии вузов. Почему стоит рассматривать развитие эндаументов-фондов и другой фандрайзинговой деятельности вузов как элемент модели нелинейного развития?

В первую очередь развитие фондов целевого капитала позволяет получить вузам некоторую финансовую самостоятельность, иными словами, финансовую автономию.

Обратимся к самому понятию автономии университета. Как отмечают А. Волков и Д. Мельник, автономию университета следует понимать сквозь призму трех основных аспектов. Во-первых, при автономии университет имеет возможность «самостоятельно определять траекторию своего развития, формировать видение себя и своего влияния на мир». Во-вторых, это академическая свобода, а именно «принципы свободы и преподавания и свободы исследований», которые должны являться основополагающими для современных исследовательских университетов. В-третьих, автономия университета предполагает возможность для студента формировать свою собственную траекторию обучения. При этом авторы статьи отмечают, что в условиях государственного финансирования зависимость от одного источника, а именно от государственных субсидий, снижает самостоятельность вузов [3].

С другой стороны, эндаумент-фонды становятся проявлением развития взаимоотношений вузов с бизнес-средой. В этой связи можно говорить о двух 
моментах. С одной стороны, представители бизнеса должны понимать, зачем им давать деньги вузам на безвозмездной основе, так как бизнес-структуры привыкли получать выгоду от любого своего действия. Эта проблема относится к области развития социальной ответственности бизнеса, которая, на наш взгляд, сегодня слабо развита в российских реалиях. Толчком в данном вопросе может стать одна из последних инициатив государства, в соответствии с которой бизнесу предлагается нарастить участие в фондах целевого капитала и помочь обновлению оборудования в обмен на льготу по налогу на прибыль (не более 1,5 \% от общего дохода от реализации) [4]. Принятая мера является искусственной. Государство пытается запустить процесс развития эндаументов-фондов за счет финансовой выгоды для бизнеса. На наш взгляд, названная мера противоречит философии пожертвования, которая базируется на принципах безвозмездности, социальной ответственности, а не на получении финансовой выгоды. С этой позиции инициатива государства кажется малоэффективной и краткосрочной.

Другой вопрос, который возникает при рассмотрении эндаумент-фондов как признака развития взаимоотношения с бизнесом, - это, как отмечалось выше, отсутствие автономии вузов от государства. Сейчас ведущие университеты страны находятся в сильной зависимости от инициатив Министерства образования и науки РФ. Руководство вузов работает над отчетностью перед государством, а не обществом. Если обратить внимание на ведущие западные университеты (например, США и Великобритании), которые занимают высокие позиции в международных рейтингах, то они практически полностью автономны от государства или региональной власти [3]. Эти вузы озабочены не отчетностью перед министрами образования или иными должностными государственными и муниципальными чиновниками, а проблемами сохранения своего статуса и репутации в глазах абитуриентов, студентов, выпускников, регионального сообщества, бизнеса, международного академического сообщества.

Для дальнейшей оценки эндаумент-фондов как элемента нелинейной модели развития вуза обратимся к существующим исследованиям из разных стран, в рамках которых изучаются вопросы формирования и развития эндаумент-фондов как у себя на родине, так и в масштабах всего мира.

Стоит отметить, что работы в данной области зарубежных ученых отличаются от работ их российских коллег. Первые акцентируют большее внимание на эффективности развития фондов целевого капитала, на их инвестиционном портфеле. Это связано, прежде всего, с тем, что история создания эндаумент-фондов за рубежом насчитывает века.

Так, в исследовании Г. Роузен и А. Шапингтон поднимается вопрос о том, влияет ли общий объем доходов, которые поступают в университет, на инвестиционную политику управления эндаумент-фондами [5]. Авторы исследования обнаружили, что при стабильных доходах вуза менеджеры эндаумен- 
тов-фондов формируют более рискованный инвестиционный портфель, нежели в ситуации, когда доходы вуза имеют динамический характер.

Схожий характер исследования, например, в работе С. Диммокка, который изучает влияние внешних факторов риска на инвестиционный портфель эндаумент-фондов, где под внешними факторами автор понимает волатильность нефинансовых доходов университета [6].

Российские же исследования в большинстве своем обращены к общему пониманию феномена эндаумент-фондов, их актуальности и применимости в российских условиях, сравнению с западными аналогами.

Так, в исследовании Э.А. Дьячковой рассматриваются существующие в мировой практике методики управления доходами от эндаумента и возможность их применения в российских университетах на примере НИУ «Высшая школа экономики» [7]. Во многих российских исследованиях большое внимание уделяется проблемам создания фондов в России. О.В. Касенко [8] и Д.Г. Сандлер [9] выделяют следующие проблемы:

• отсутствие достаточного количества доноров и неразвитость в менталитете граждан ценностей благотворительности и пожертвований;

- неразвитость инструментария мотивации к пожертвованиям;

- незрелость российского фондового пространства;

- отсутствие достаточных налоговых льгот и преимуществ для меценатов;

- неразвитость инструментов фандрайзинговой деятельности;

- незаинтересованность топ-менеджмента вузов высоким минимальным пороговым размером фонда (3 млн руб.);

- отсутствие достаточного опыта доверительного управления фондами;

- зависимость интереса к эндаумент-фондам от динамики экономической конъюнктуры.

Таким образом, в первой части статьи мы постарались доказать, что эндаумент-фонды - это элемент нелинейной модели развития экономики вузов. Перейдем к конкретному анализу эндаументов-фондов российских вузов и их классификации.

Развитие эндаумент-фондов в вузах России и их классификация. Создание и развитие эндаумент-фондов в России стало возможным после появления Федерального закона от 30 декабря 2006 г. № 275-Ф3 «О порядке формирования и использования целевого капитала некоммерческих организаций». В 2011 году в закон были внесены некоторые изменения, согласно которым «целевой капитал некоммерческой организации - часть имущества некоммерческой организации, которая формируется и пополняется за счет пожертвований ... и (или) за счет имущества, полученного по завещанию, а также за счет неиспользованного дохода от доверительного управления указанным имуществом и передана некоммерческой организацией в доверительное управление управляющей компании в целях получения дохода, исполь- 
зуемого для финансирования уставной деятельности такой некоммерческой организации или иных некоммерческих организаций» [10].

В ходе нашего исследования были собраны из открытых источников статистические данные по наиболее известным и крупным 27 эндаументфондам российской высшей школы (табл. 1).

Таблица 1

Динамика развития эндаумент-фондов в российских вузах, млн руб.

\begin{tabular}{|c|c|c|c|c|c|c|c|c|}
\hline Вуз & 2008 & 2009 & 2010 & 2011 & 2012 & 2013 & 2014 & 2015 \\
\hline $\begin{array}{l}\text { Европейский университет в Санкт- } \\
\text { Петербурге }\end{array}$ & 20,7 & 215,6 & 369 & 409,2 & 825,6 & 1213 & 1254 & 1516,1 \\
\hline $\begin{array}{l}\text { Московский государственный инсти- } \\
\text { тут международных отношений }\end{array}$ & 385 & 499 & 621 & 854 & 1091 & 1205 & 1262 & 1415 \\
\hline $\begin{array}{l}\text { Санкт-Петербургский государствен- } \\
\text { ный университет }\end{array}$ & & & 277,3 & 680,9 & 1012 & 1053 & 1040 & 1004 \\
\hline Российская экономическая школа & 17 & 74,1 & 224,2 & 245,1 & 281,5 & 323 & 358 & 320 \\
\hline Высшая школа экономики & 25,6 & 30,7 & 35,4 & 38 & 40,7 & 43,1 & 67,5 & 213,9 \\
\hline $\begin{array}{l}\text { Северо-Восточный федеральный } \\
\text { университет }\end{array}$ & & & & & 63 & 101,3 & 152,3 & 205 \\
\hline $\begin{array}{l}\text { Национальный исследовательский } \\
\text { технологический университет } \\
\text { «МИСиС» }\end{array}$ & & & & 3,1 & 5,8 & 34,4 & 68,2 & 128,3 \\
\hline $\begin{array}{l}\text { Московский государственный уни- } \\
\text { верситет им. М.В. Ломоносова }\end{array}$ & & & & & & & 110 & \\
\hline \begin{tabular}{|l|} 
Финансовый университет при Прави- \\
тельстве Российской Федерации
\end{tabular} & 5 & 18,5 & 22,6 & 39 & 48,7 & 64,5 & 79 & 83,3 \\
\hline Уральский федеральный университет & & & & & 12 & 23 & 45 & 57 \\
\hline $\begin{array}{l}\text { Православный Свято-Тихоновский } \\
\text { гуманитарный университет }\end{array}$ & & & & & 6,3 & 65,1 & 61,2 & 52,7 \\
\hline $\begin{array}{l}\text { Санкт-Петербургский государствен- } \\
\text { ный экономический университет }\end{array}$ & & & & & & & & 48 \\
\hline $\begin{array}{l}\text { Томский политехнический } \\
\text { университет }\end{array}$ & & & & & & & 17,3 & 24,2 \\
\hline $\begin{array}{l}\text { Новосибирский государственный } \\
\text { университет }\end{array}$ & & & & & & 14,4 & 23,2 & 24,1 \\
\hline Южный федеральный университет & & 8,3 & 9,7 & 11,1 & 12,3 & 12,9 & 15,4 & 20,1 \\
\hline $\begin{array}{l}\text { Тюменский государственный уни- } \\
\text { верситет }\end{array}$ & & 10,4 & 12,9 & 13,5 & 14,5 & 15,1 & 14,6 & 17,3 \\
\hline $\begin{array}{l}\text { Санкт-Петербургский политехниче- } \\
\text { ский университет Петра Великого }\end{array}$ & & & & & & 5,3 & 9 & 14,1 \\
\hline $\begin{array}{l}\text { Воронежский государственный уни- } \\
\text { верситет }\end{array}$ & & & & & & 13 & 13,3 & \\
\hline $\begin{array}{l}\text { Мордовский государственный уни- } \\
\text { верситет им. Н.П. Огарева }\end{array}$ & & & & & & & 10,1 & 10,1 \\
\hline $\begin{array}{l}\text { Томский государственный универ- } \\
\text { ситет }\end{array}$ & & & & & 6,3 & 6,3 & 10,1 & \\
\hline
\end{tabular}


Окончание табл. 1

\begin{tabular}{|l|c|c|c|c|c|c|c|c|}
\hline \multicolumn{1}{|c|}{ Вуз } & 2008 & 2009 & 2010 & 2011 & 2012 & 2013 & 2014 & 2015 \\
\hline $\begin{array}{l}\text { Самарский национальный исследова- } \\
\text { тельский университет им. академика } \\
\text { С.П. Королева }\end{array}$ & & & & & & & \\
\hline $\begin{array}{l}\text { Нижегородский государственный } \\
\text { университет им. Н.И. Лобачевского }\end{array}$ & & & & & & 4,4 & 6 & 6,5 \\
\hline $\begin{array}{l}\text { Омский государственный универси- } \\
\text { тет им. Ф.М. Достоевского }\end{array}$ & & & & & & & & \\
\hline $\begin{array}{l}\text { Волгоградский государственный } \\
\text { университет }\end{array}$ & & & & 4,3 & 4,8 & 5,1 & 5,2 & 6,1 \\
\hline $\begin{array}{l}\text { Донской государственный техниче- } \\
\text { ский университет }\end{array}$ & & & & & & & & \\
\hline $\begin{array}{l}\text { Российский государственный техно- } \\
\text { логический университет им. К.Э. Ци- } \\
\text { олковского }\end{array}$ & & & & & & & & \\
\hline $\begin{array}{l}\text { Пермский государственный уни- } \\
\text { верситет }\end{array}$ & & & & & & & & \\
\hline
\end{tabular}

В табл. 1 представлены данные о фондах, по которым удалось найти информацию из открытых источников, в том числе с сайтов университетов, в порядке убывания объема фонда. В таблицу вошли только фонды, которые переданы под контроль управляющих компаний, т.е. фонды свыше 3 млн руб.

Большинство представленных вузов государственные. При этом 3 частных вуза (Европейский университет в Санкт-Петербурге, Российская экономическая школа, Православный Свято-Тихоновский гуманитарный университет) находятся в первой половине таблице. Лидером по объему фонда на сегодняшний день является частный Европейский университет в Санкт-Петербурге.

В ходе анализа данных табл. 1, финансовых показателей деятельности фондов, а также стратегии управления фондами автор пришел к выводу, что фонды целевого капитала вузов можно классифицировать по следующим основаниям.

1. По территориальному признаку. Географически фонды можно делить как по субъектам, так и по федеральным округам, что, на наш взгляд, является более целесообразным в связи с малым количеством фондов. Распределение фондов относительно федеральных округов РФ представлено в табл. 2.

По данным таблицы можно сделать вывод, что развитие эндаументфондов в Центральном федеральном и Северо-Западном федеральных округах намного превосходит развитие «провинциальных» фондов. Как следствие, развитие фондов в провинциальных регионах должно иметь государственную поддержку. 
Распределение эндаумент-фондов вузов относительно федеральных округов РФ, 2015 год

\begin{tabular}{|l|c|c|l|}
\hline $\begin{array}{c}\text { Федеральный } \\
\text { округ }\end{array}$ & $\begin{array}{c}\text { Количество } \\
\text { фондов }\end{array}$ & $\begin{array}{c}\text { Общий объем } \\
\text { фондов, млн руб. }\end{array}$ & \multicolumn{1}{|c|}{ Вуз-лидер } \\
\hline Северо-Западный & 4 & 2582,2 & $\begin{array}{l}\text { Европейский университет в Санкт- } \\
\text { Петербурге }\end{array}$ \\
\hline Центральный & 10 & 2349,5 & $\begin{array}{l}\text { Московский государственный инсти- } \\
\text { тут международных отношений }\end{array}$ \\
\hline Дальневосточный & 1 & 205 & $\begin{array}{l}\text { Северо-Восточный федеральный уни- } \\
\text { верситет }\end{array}$ \\
\hline Уральский & 2 & 74,3 & Уральский федеральный университет \\
\hline Сибирский & 5 & 71,3 & Томский политехнический университет \\
\hline Южный & 3 & 30,8 & Южный федеральный университет \\
\hline Поволжский & 2 & 13,4 & $\begin{array}{l}\text { Мордовский государственный универ- } \\
\text { ситет им. Н.П. Огарева }\end{array}$ \\
\hline
\end{tabular}

2. По объему цеелевого капитала. По данному критерию фонды могут быть классифицированы условно на формирующиеся (до 3 млн руб.), малые (до 50 млн руб.), средние (до 500 млн руб.), большие (свыше 500 млн руб.). Распределение фондов по объему целевого капитала представлено на рис. 1.

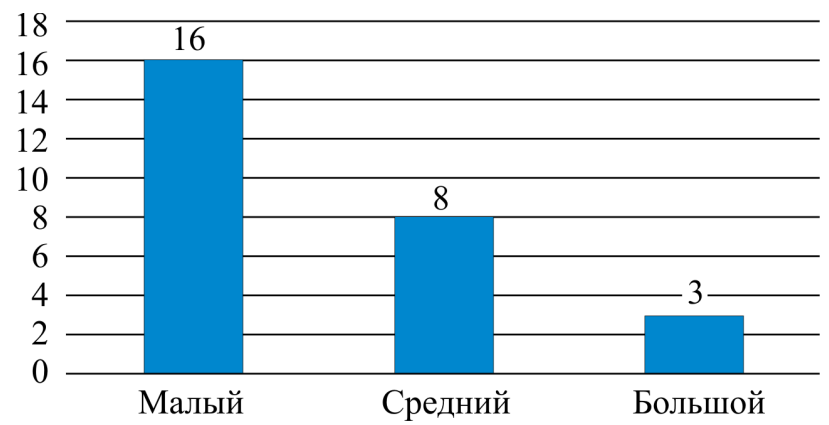

Рис. 1. Распределение эндаумент-фондов по объему

Большее половины исследуемых фондов относится к категории малых, что в очередной раз подчеркивает «зачаточное» состояние эндаументов в российских вузах.

3. По стратегии формирования фонда. В основе данной классификации лежит два критерия: количество пожертвований (единичные, умеренные, массовые) и объем пожертвований. Первоначально такая классификация была предложена в работе исследователей Уральского федерального университета [9, с. 136]. Вариант классификации по этому критерию представлен в виде матрицы (рис. 2). 


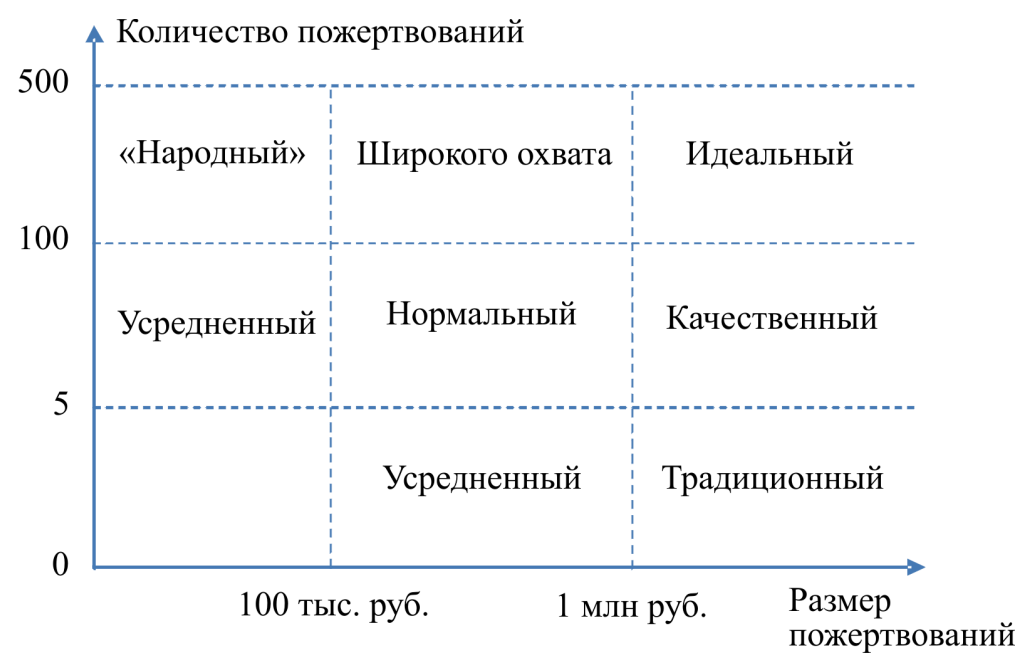

Рис. 2. Классификация эндаумент-фондов по стратегии их формирования

Подавляющее большинство исследуемых фондов можно поместить в правый нижний угол представленной матрицы. Действительно, у большинства фондов есть несколько крупных жертвователей. В основном это крупные бизнесмены, бывшие выпускники вузов.

К «народному» эндаументу можно отнести эндаумент Уральского федерального университета, который проводит достаточно продуктивную политику по сбору небольших пожертвований (от 1000 руб.) с физических лиц выпускников, студентов, других заинтересованных групп [9].

4. По стратегии расходования. Классификация может быть произведена с точки зрения направления расходов фондов целевого капитала. Как правило, эти статьи прописываются в уставных документах при создании эндаументфондов и содержат следующие направления (на примере Уральского федерального университета):

- качество образования;

- наука и научные исследования;

- талантливая молодежь;

- кадровый потенциал;

- продвижение имени университета.

5. По инвестищионной стратегии. В зависимости от инвестиционного портфеля, которым руководит управляющая компания фонда, фонды могут быть разделены на консервативные (используют финансовые инструменты с фиксированной доходностью), умеренно-консервативные, рискованные (используют высокодоходные финансовые инструменты).

Как показывает российский опыт, большинство фондов придерживаются консервативной стратегии инвестирования. Одной из причин этого является 
то, что в России университетам запрещено на законодательном уровне вкладывать средства в высокодоходные финансовые инструменты. При этом стоит отметить, что за рубежом проявляется следующая тенденция: чем больше размер эндаумент-фонда, тем рискованнее инвестиционная стратегия [11].

Заключение. Подчеркнем еще раз, что развитие эндаумент-фондов в вузах - это проявление нелинейной модели развития вузов. На сегодняшний день создано немало фондов, но при этом сохраняются и проблемы в их работе.

Автор попытался на основе собранных статистических данных представить основания для классификации эндаумент-фондов, а именно: по территориальному признаку, по объему целевого капитала, по стратегии формирования фонда, по стратегии расходования, по инвестиционной стратегии.

Статья подготовлена при финансовой поддержке Российского научного фонда (проект № 16-18-10046 «Формирование нелинейной модели российского высшего образования в регионе в условиях экономической и социальной неопределенности»).

\section{Список литературы}

1. Зборовский Г.Е., Амбарова П.А. Концептуальные основы перехода к нелинейной модели высшего образования в регионе // Экономика региона. - 2016. - Т. 12, № 4. - С. 1157-1166.

2. Кульпин С.В. Нелинейность в экономике вузов России // Вестник Пермского национального исследовательского политехнического университета. Социально-экономические науки. - 2016. - № 4. - С. 67-78.

3. Волков А., Мельник Д. Автономность и публичность университета [Электронный ресурс] // Ведомости. - 01.02.2017. - URL: http://www.vedomosti.ru/opinion/articles/2017/02/01/675685-avtonomnost-universiteta (дата обращения: 23.05.2017).

4. Ученье прибыль бережет [Электронный ресурс] // Коммерсант.04.05.2017. - URL: https: //www.kommersant.ru/doc/3288835 (дата обращения: 10.06.2017).

5. Rosen H., Sappington A.J. What Do University Endowment Managers Worry About? An Analysis of Alternative Asset Investments and Background Income // Education Finance and Policy. - 2016. - № 11 (4). - P. 404-425.

6. Dimmock S.G. (2012). Background Risk and University Endowment Funds // Review of Economics and Statistics. - 2012. - № 94 (3). - P. 789-799.

7. Дьячкова Э.А. Управление доходами от целевого капитала в университетах // Вопросы образования. - 2016. - № 1.- С. 225-244.

8. Касенко О.В. Проблемы развития эндаумент-фондов вузов в России // Проблемы развития современной экономики. - 2016. - № 7. - С. 9-12.

9. Особенности модели «народного» эндаумента на примере Уральского федерального университета / Д.Г. Сандлер, А.Д. Преснякова, Д.А. Мельник, 
С.В. Макшанова, Н.А. Останина // Университетское управление: практика и анализ. - 2016. - № 4. - С. 134-149.

10. О порядке формирования и использования целевого капитала некоммерческих организаций [Электронный ресурс]: Федер. закон от 30.12.2006 № 275-Ф3. - URL: http://www.consultant.ru/document/ cons_doc_LAW_64939/ (дата обращения: 25.05.2017).

11. Абаев А.П. Анализ показателей деятельности вузовских эндаументфондов на современном этапе // Вестник Московского финансово-юридического университета. - 2016. - № 3. - С. 165-178.

\section{References}

1. Zborovskii G.E., Ambarova P.A. Kontseptual'nye osnovy perekhoda k nelineinoi modeli vysshego obrazovaniia $\mathrm{v}$ regione [Conceptual foundations of transition to the nonlinear models of higher education in the Region]. Ekonomika regiona, 2016, vol. 12, no. 4, pp. 1157-1166.

2. Kul'pin S.V. Nelineinost' v ekonomike vuzov Rossii [Non-linearity in economics of Russian high schools]. PNRPU sociology and economics bulletin, 2016, no. 4, pp. 67-78.

3. Volkov A., Mel'nik D. Avtonomnost' i publichnost' universiteta [Autonomy and publicity of the university]. Vedomosti, 2017. Available at: http:// www.vedomosti.ru/opinion/articles/2017/02/01/675685-avtonomnost-universiteta (accessed 23 May 2017).

4. Uchen'e pribyl' berezhet [Universities waste not]. Kommersant, 2017. Available at: https://www.kommersant.ru/doc/3288835 (accessed 10 June 2017).

5. Rosen H., Sappington A. J. What do university endowment managers worry about? An analysis of alternative asset investments and background income. Education finance and policy, 2016, no. 11 (4), pp. 404-425.

6. Dimmock S.G. Background risk and university endowment funds. Review of economics and statistics, 2012, no. 94(3), pp. 789-799.

7. D'iachkova E.A. Upravlenie dokhodami ot tselevogo kapitala v universitetakh [Managing endowment fund income in universities]. Voprosy obrazovaniia, 2016, no. 1, pp. 225-244.

8. Kasenko O.V. Problemy razvitiia endaument-fondov vuzov v Rossii [Problems of developing endowment funds in the universities of Russia]. Problemy razvitiia sovremennoi ekonomiki, 2016, no. 7, pp. 9-12.

9. Sandler D.G., Presniakova A.D., Mel'nik D.A., Makshanova S.V., Ostanina N.A. Osobennosti modeli "narodnogo" endaumenta na primere Ural'skogo federal'nogo universiteta [Public endowment model at the Ural Federal University: issues and specifics]. Universitetskoe upravlenie: praktika i analiz, 2016, no. 4, pp. 134-149.

10. Federal'nyi zakon ot 30.12.2006 no. 275-FZ 29 "O poriadke formirovaniia $\mathrm{i}$ ispol'zovaniia tselevogo kapitala nekommercheskikh organizatsii" [Federal Law 
of 30.12.2006 no. 275-FZ 29 "On improving the mechanism of formation and use of non-profit organization endowment"]. Available at: http://www.consultant.ru/document/cons_doc_LAW_64939/(accessed 25 May 2017).

11. Abaev A.P. Analiz pokazatelei deiatel'nosti vuzovskikh endaumentfondov na sovremennom etape [Performance analysis of university endowment funds at the present stage]. Vestnik Moskovskogo finansovo-iuridicheskogo universiteta, 2016, no. 3, pp. 165-178.

Оригинальность $92 \%$

Получено 15.06.2017 Принято 25.07.2017 Опубликовано 29.12.2017

\author{
S.V. Kulpin
}

\title{
ENDOWMENTS AS AN ELEMENT OF THE NON-LINEAR MODEL OF HIGHER EDUCATION'S ECONOMIC DEVELOPMENT
}

Non-linearity in the economic environment of Russian higher education appeared with penetration of capitalism into national economic system. The Soviet model of financing higher schools was strictly linear. There were no other sources for financing universities activities apart from state funding for vocational training and researching. The outcomes of higher education institutions development were strictly defined and predictable. Modern Russian universities strive to raise extra funds, which demonstrates non-linearity in the economic and financial models of university operation.

One of the elements of non-linear model of higher education development is establishing endowment funds. Endowment is an integral part of university strategy aimed to be more independent and autonomous from the state. Some experts consider endowment funds to be social investment institutions that are not linked with growth of government expenditures and social sphere commercialization. Russian higher schools adopted practices of the Western countries that have been developing endowment for a long time. It is important to note that endowment funds have similar features in different countries, if they are considered in the context of market economy institutions. However, there may be differences in legislation, history, culture, etc. between the countries.

The article proposes to assess endowment funds prospects at Russian universities, including their feasibility and main formation and development challenges. It is suggested to consider experience of successfully implemented endowment funds in Russian higher education. It is also proposed to classify the endowment funds based on the Russian case studies.

The scientific novelty of this research consists in describing the current state of the Russian universities endowment funds, as well as in attempt to classify them.

Keywords: endowment, target capital fund, higher education, non-linear model of higher education development, Russian universities.

Sergey V. Kulpin - Candidate of Economic Sciences, Senior Lecturer, Dept. of Integrated Marketing Communications and Branding, Institute of Public Administration and Entrepreneurship, Ural Federal University named after the First President of Russia B.N. Yeltsin, e-mail: s.v.kulpin@urfu.ru.

Received 15.06.2017

Accepted 25.07.2017

Published 29.12.2017 